\title{
The socio-economic impact of agro-tourism activity on fishing communities in Malaysia
}

\begin{abstract}
The main attempt of this study is to explore the socio-economic impacts of agro-tourism activity of fishing communities in Malaysia. As many studies with regard to tourism are placing their focus on tourism in general, less has been placed on agro-tourism and the expected findings from this study can fill the existing gap. This is a quantitative study where data were gained through developed questionnaires. A total of 880 respondents from eight Desa Wawasan Nelayan villages had been selected randomly. Findings have confirmed that agro-tourism activities were able to increase villagers' income, provide employment opportunities and increase demand for local products. Albeit its advantages were economic, it can be concluded that agro-tourism activities embolden healthy relationships within the community while at the same time uplifting their quality of life.
\end{abstract}

Keyword: Social benefits; Economic benefits; Agro-tourism; Community development; Malaysia 